\title{
EFFECT OF DIAMINOSILANE DERIVATIVE ON THERMAL AND SWELLING BEHAVIOUR OF ACRYLIC ACID BASED HYDROPHILIC COMPOSITES
}

\author{
Olga Slisenko ${ }^{1,}$, Iryna Bei ${ }^{1}$, Vira Budzinska ${ }^{1}$
}

https://doi.org/10.23939/chcht16.01.059

\begin{abstract}
Organic-inorganic hydrophilic composites based on sodium polyacrylate (PAANa) and poly- $N-(2-$ aminoethyl)-3-aminopropyltrimethoxysilane (PAPTMS) showed the improved swelling capacity at incorporation of PAPTMS. Changing of non-Fickian to Super case II swelling behaviour is observed at $20 \mathrm{wt} \%$ PAPTMS content. Enhancing of thermal stability and heat-resistance index of composite hydrogels compared to PAA is shown.
\end{abstract}

Keywords: polyacrylic acid, hydrogel, organic-inorganic composites, swelling behaviour.

\section{Introduction}

Hydrogels are hydrophilic, three-dimensional, polymer networks that can absorb and retain large amounts of water. ${ }^{1}$ However, areas of their applications are often limited by poor mechanical properties. In recent decades, a new type of materials, namely organicinorganic hybrid materials, has emerged in order to solve this problem. ${ }^{2,3}$ One of these approaches is the development of dual networks (DN), which provide a new concept for strengthening the mechanical properties of hydrogels consisting of brittle and stiff first network while the second network is ductile and soft, showing remarkable high compressive, tensile strength and toughness. ${ }^{4,5}$ Terms "double networks" or "dual networks" are used for a unique type of interpenetrating polymer networks (IPN) first described by Gong et al. ${ }^{6}$ in 2003. Such networks exhibit a nonlinear enhancement of mechanical strength, high resistance to wear and high fracture strength, up to 17 times comparatively with that of its component networks containing $60-90 \%$ of water. The concept of DN hydrogels has shown that the first rigid network dissipates energy and increases the resistance against the crack creep, and the flexible second

\footnotetext{
${ }^{1}$ Institute of Macromolecular Chemistry of the National Academy of Sciences of Ukraine,

48 Kharkivs'ke Sh., 02160 Kyiv, Ukraine

olgaslisenko@ukr.net

(C) Slisenko, O.; Bei, I.; Budzinska, V., 2022
}

network provides elasticity to the hydrogel. ${ }^{7}$ However, as soon as DN hydrogel is damaged at high strain, the rupture of the first network will result in a bond breakage and, as a consequence, loosing most of its mechanical properties. $^{8}$

In order to improve the mechanical properties of the hydrogels, some inorganic components have been introduced to the acrylic component. Shishan Xue et al. ${ }^{9}$ reported about fabrication of novel composite hydrogels based on poly(acrylic acid) and surface-modified boron nitride nanosheets $\left(\mathrm{PAA} / \mathrm{BNNS}-\mathrm{NH}_{2}\right.$ ) through physical interactions: molecular-scale metal coordination interaction between $-\mathrm{COOH}$ of PAA and $\mathrm{Fe}^{3+}$ and nanoscale $\mathrm{H}$-bond between $-\mathrm{COOH}$ of $\mathrm{PAA}$ and $-\mathrm{NH}_{2}$ of BNNS-NH ${ }_{2}$. Obtained composites are characterised by excellent mechanical properties (including enhanced fracture stress, elongation, toughness, Young's modulus, and dissipated energy) as well as self-healing ability. Zhong et $a l .{ }^{10}$ graphene oxide /poly(acrylic acid) nanocomposite hydrogels with significantly improved mechanical properties. The invariably porous nanofiller, the nanobentonite (clay), ${ }^{11}$ was introduced to acrylic acid (monomer) to enhance heavy metal removal capacity up to $\sim 20 \mathrm{mg} / \mathrm{g}$ (according to Freundlich isotherm). Increasing the amount of filler from 0.25 to $2 \mathrm{wt} \%$ leads to $94 \%$ of removal capacity. A novel hydrogel composite (starch-g-poly(acrylic acid)/organo-mordenite) with increased swelling capabilities (the maximum water absorbency is $655 \mathrm{~g} / \mathrm{g}$ when $10 \mathrm{wt} \%$ organo-mordenite is incorporated) and excellent environmental-responsiveness was synthesized by inverse suspension copolymerization. ${ }^{12}$ It is shown that the water absorbency of the hydrogel composite is affected by the $\mathrm{pH}$ value, species and concentration of the salt solutions. In addition, the swelling behaviour of the hydrogel composite is Fickian transport, and the swelling process fits the Schott's model. Although PAA possesses lots of attractive properties, its poor thermal and mechanical properties limit the application of the hydrogel produced from PAA to a certain extent. ${ }^{13}$ The most serious limitations of organic gels are due to their weak and brittle nature as well as insufficient swelling. 
To overcome some limitations of PAA gels a new type of organic-inorganic composite (OIC) hydrogels based on partially neutralized acrylic acid and N-(2aminoethyl)-3-aminopropyltrimethoxysilane (APTMS) were prepared. Synthesized partially neutralized PAA (PAANa)/PAPTMS hydrogels show remarkable improvements in swelling properties, thermal stability as a result of reinforcing the organic network by the inorganic one. Inorganic component acts as a multifunctional crosslinking agent through non-covalent interactions instead of using organic cross-linkers.

\section{Experimental}

\subsection{Materials}

Acrylic acid monomer (AA) and ammonium persulphate (APS) were purchased from Merck (Darmstad, Germany) and used without further purification. $N, N^{\prime}-$ methylene-bis(acrylamide) (MBA), $N$-(2-aminoethyl)-3aminopropyltrimethoxysilane (APTMS) and sodium hydroxide were supplied by Aldrich Chemicals (Milwaukee, US) and used as received. Deionized water (DW) was utilized during the whole experiment.

\subsection{Synthesis of Organic/Inorganic Dual Network Composites}

Syntheses were fulfilled by simultaneous crosslinking processing, which includes a combination of free radical polymerization of sodium acrylate (AANa) in the presence of MBA cross-linker and hydrolysis of silica precursors and catalytically-induced condensation of the resulting hydroxyl groups of APTMS (from 5 to $20 \mathrm{wt} \%$ ) to form a network structure. Preliminary AA was neutralised with $10 \% \mathrm{NaOH}$ solution (neutralization degree was $10 \%$ ), for all further experiments sodium salt of AA was used. AANa, MBA (content of MBA varied from 0.3 to $1 \mathrm{wt} \%$ ) and radical initiator (APS) were mixed with water under stirring at room temperature for $10 \mathrm{~min}$. Then predetermined amounts of APTMS solution in water, acidified with $\mathrm{HCl}$, were added. Syntheses were carried out at $343-353 \mathrm{~K}$ for $5 \mathrm{~h}$. Obtained poly(sodium acrylate) (PAANa)/polyAPTMS (PAPTMS) samples were purified by washing with water for removing of unreacted monomers. Hybrid composite hydrogels with different silica content (from 5 to $20 \mathrm{wt} \%$ ) were successfully prepared.

\subsection{Methods}

Dried and pounded hydrogels powder was pressed with $\mathrm{KBr}$ and Fourier-transform infrared (FTIR) spectra of the composite hydrogels were recorded with a Bruker
Tensor 27 DTGS spectrometer at a wavenumber range of $4000-600 \mathrm{~cm}^{-1}$ with a resolution of $2 \mathrm{~cm}^{-1}$. The spectra were normalized by height before spectra subtraction was performed.

Thermal stability of the samples was studied by Thermogravimetric Analysis (TGA) using the TGA Q500 (TA Instruments) equipment. TG traces were registered in the temperature range from 298 to $1073 \mathrm{~K}$ at a heating rate of $20 \mathrm{~K} \cdot \mathrm{min}^{-1}$ at continuous evacuation of volatile products of degradation.

The swelling ability of gels in a free state at isothermic regime $291 \pm 1 \mathrm{~K}$ was studied by immersion of dried samples in distilled water $(\mathrm{pH}=6.6)$ and in buffer solution $\left(\mathrm{Na}_{2} \mathrm{~B}_{2} \mathrm{O}_{4} \cdot 10 \mathrm{H}_{2} \mathrm{O}, \mathrm{pH}=9.18\right)$. The sample was placed in the swelling solution and the weight of the swollen sample was measured along the sample exposition periodically taking out and weighting the sample (time of measuring was $<1 \mathrm{~min}$ ). Before weighting the excessive surface liquid was gently removed by filter paper. The degree of swelling $\left(W_{t}\right)$ for each sample at time $t$ was calculated using equation:

$$
W_{t}=\frac{m_{t}-m_{0}}{m_{0}}
$$

where $m_{t}$ and $m_{0}$ are the sample weight at any given time, and in the initial dry state, respectively.

\section{Results and Discussion}

The formation of siloxane network during the selfcondensation of APTMS was confirmed by FTIR (Fig. 1). Polycondensation of APTMS leads to shifting of absorption band at $3349 \mathrm{~cm}^{-1}$, which is ascribed to the asymmetrical $\mathrm{N}-\mathrm{H}$ stretching modes, to $3358 \mathrm{~cm}^{-1}$. The $\mathrm{N}-\mathrm{H}$ bending vibration of primary amines in APTMS is observed at $1572 \mathrm{~cm}^{-1}$ and it is shifted to $1602 \mathrm{~cm}^{-1}$ after condensation.

The $\mathrm{Si}-\mathrm{O}-\mathrm{CH}_{3}$ groups of APTMS hydrolyze with the formation of hydroxyl groups $(\mathrm{Si}-\mathrm{OH})$ that selfcondense to form $\mathrm{Si}-\mathrm{O}-\mathrm{Si}$ bonds in linear and cyclic structures. ${ }^{14}$ It is known that as the siloxane chains become longer or branched, the $\mathrm{Si}-\mathrm{O}-\mathrm{Si}$ absorption becomes broader and more complex, showing two or more overlapping bands. Self-condensation of $\mathrm{Si}-\mathrm{OH}$ and formation of $\mathrm{Si}-\mathrm{O}-\mathrm{Si}$ network are proved by splitting of the peak in the wavenumber region of $726-860 \mathrm{~cm}^{-1}$ of initial APTMS after self-condensation. ${ }^{15}$ As a result, two intensive infrared bands appear at 1115 and $1040 \mathrm{~cm}^{-1}$ assigned to asymmetric and symmetric stretching vibrations of $\mathrm{Si}-\mathrm{O}$ bonds in $\mathrm{Si}-\mathrm{O}-\mathrm{Si}$ network, respectively. New bands at 2974, 2928 and $2874 \mathrm{~cm}^{-1}$ correspond to $v_{a s}(\mathrm{C}-\mathrm{H}) \mathrm{CH}_{3}, \quad v_{a s}(\mathrm{C}-\mathrm{H}) \mathrm{CH}_{2}$ and $v_{s}(\mathrm{C}-$ $\mathrm{H}) \mathrm{CH}_{3}$ from APTMS. 




Fig. 1. FTIR spectra of (PAPTMS) (1), $\mathrm{PAANa} / \mathrm{PAPTMS}=90 / 10$ (2) and PAANa (3)

Analysis of PAANa and composite hydrogel spectra (line 2), shows disappearing of the absorption bands at 3080 and $2975 \mathrm{~cm}^{-1}$ assigned to the stretching vibrations of $\mathrm{C}-\mathrm{H}$ bonds of unsaturated $=\mathrm{CH}_{2}$ and $=\mathrm{CH}$ groups of acrylic monomer, respectively. At the same time the absence of the absorption band at $1615 \mathrm{~cm}^{-1}$ corresponded to the stretching vibrations of $\mathrm{C}=\mathrm{C}$ bonds of acrylic monomer is due to the polymerization of AA into PAA. The PAANa spectrum shows a broad peak at approximately $1638-1734 \mathrm{~cm}^{-1}$ (maximum at $1714 \mathrm{~cm}^{-1}$ ) corresponded to the carboxylic $\mathrm{C}=\mathrm{O}$ moiety (in $\mathrm{AA}$ it appears as a distinctive peak at $1695 \mathrm{~cm}^{-1}$ ). Partial neutralization of AA causes appearance of $v_{a s}\left(\mathrm{COO}^{-}\right)$at 1553 and $1410 \mathrm{~cm}^{-1}$ at PAANa spectrum, which are also present in PAANa/PAPTMS $=90 / 10$ composite. A presence of absorbed water in the samples is identified by a characteristic band at $3311 \mathrm{~cm}^{-1}$. Fig. 1 shows shifts of characteristic absorption bands of individual components at their mixing. This phenomenon takes place due to weakening of the intramolecular hydrogen bonds of acrylic fragments of PAANa networks as a result of detachment of the organic polymer chains by the inorganic siloxane network. These changes are explained by appearing of intercomponent interactions between the constituents of different nature (absorbed water molecules affect inter-/intracomponent interactions of the composites). ${ }^{16}$

Thermal-oxidative decomposition of individual PAPTMS and PAANa, as well as of PAANa/PAPTMS composite hydrogels with PAPTMS content of 10 and $20 \mathrm{wt} \%$ has been investigated by TGA (Fig. 2) and the corresponding decomposition temperature $\left(T_{d i}\right)$ and weight loss $\left(\Delta m_{i}\right)$ data are summarized in Table 1.

TG analysis provides useful information about thermal stability, weight loss at certain temperature, heatresistance that is essential for selecting materials with the best properties for specific applications. The thermal degradation of PAANa shows three separate decomposition regions. The first decomposition region of PAANa, which is attributed to a decarboxylation reaction, starts at $543 \mathrm{~K}$ and ends at $559 \mathrm{~K}$, with a maximum decomposition rate at $552 \mathrm{~K}$. The second decomposition region, which appearance is mainly due to the anhydride formation, starts at $703 \mathrm{~K}$ and stops at $714 \mathrm{~K}$, with a maximum decomposition rate at $710 \mathrm{~K}$. The third decomposition region starts at $742 \mathrm{~K}$ and stops at $763 \mathrm{~K}$, with a maximum decomposition rate at $758 \mathrm{~K}$. The third region is attributed to the thermal degradation of corresponding polyacrylic anhydride.

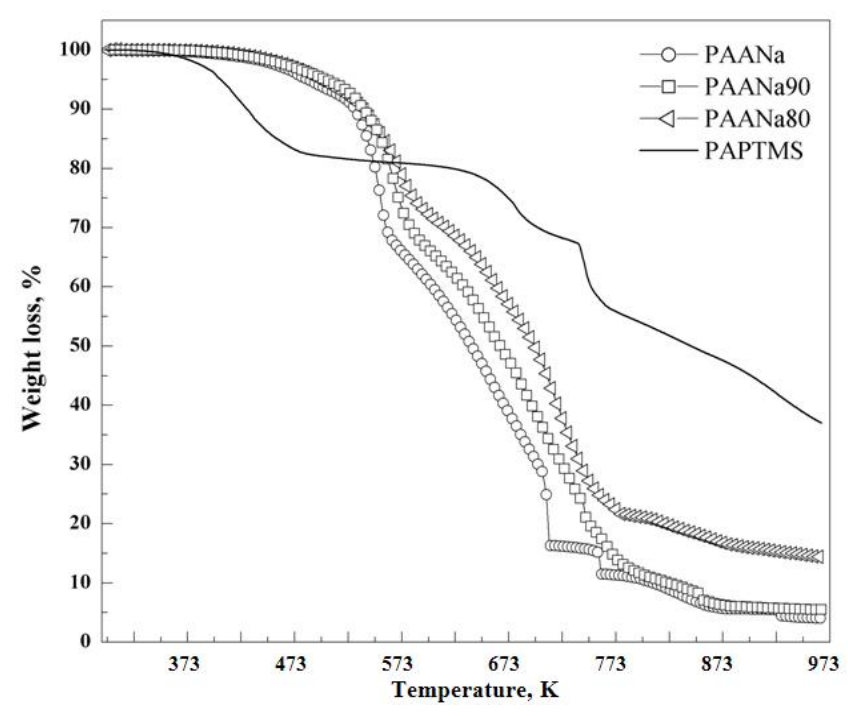

Fig. 2. Weight loss TG curves of PAANa/PAPTMS hybrid hydrophilic composites with different PAANa content

Table 1. Thermal properties of PAANa/ PAPTMS composites

\begin{tabular}{|c|c|c|c|c|c|c|c|c|}
\hline \multirow[t]{2}{*}{ Sample } & \multicolumn{4}{|c|}{$\begin{array}{c}\text { Maximal decomposition temperature, } \\
T_{d i}(\max )(\mathrm{K}) / \text { weight loss, } \Delta m_{i}(\mathrm{wt} \%) \text { at } T_{d i}(\max )\end{array}$} & \multirow{2}{*}{$\begin{array}{c}\text { Resid } \\
\text { ue,wt } \\
\%\end{array}$} & \multicolumn{2}{|c|}{$\begin{array}{l}\text { Temperatures of } 5 \% \\
\text { and } 30 \% \text { weight loss }\end{array}$} & \multirow[t]{2}{*}{$T_{\mathrm{HRI}}, \mathrm{K}$} \\
\hline & $T_{d l(\max )} / \Delta m_{l}$ & $T_{d 2(\max )} / \Delta m_{2}$ & $T_{d 3(\max )} / \Delta m_{3}$ & $T_{d 4(\max )} / \Delta m_{4}$ & & $T_{5}$ & $T_{30}$ & \\
\hline PAANa & $552 / 23.7$ & $710 / 80.4$ & $758 / 85.8$ & - & 4.04 & 485 & 559 & 398.6 \\
\hline PAANa90 & $564 / 21.0$ & $744 / 78.1$ & $775 / 86.2$ & $853 / 91.9$ & 5.45 & 501 & 581 & 408.2 \\
\hline PAANa80 & $570 / 19.7$ & $715 / 58.2$ & $775 / 78.1$ & - & 14.41 & 497 & 614 & 417.2 \\
\hline PAPTMS & $429 / 10.1$ & $677 / 25.9$ & $743 / 35.6$ & - & 37.20 & 404 & 701 & 424.5 \\
\hline
\end{tabular}


The TG curve of PAPTMS also shows three steps of decomposition. The thermal degradation of polysiloxanes occurs primarily through a heterolytic cleavage of the $\mathrm{Si}-\mathrm{O}$ main chain bonds. The reaction yields a mixture of volatile, low molecular weight products of the same chemical composition as the original polymer, mostly six- and eight-membered cyclic siloxy compounds, which are more thermodynamically stable at those degradation temperatures. ${ }^{17}$ The cleavage of organic groups bound to the silicon atoms is another process that is also possible during thermal degradation resulting in the formation of gaseous products. It is found that PAPTMS begins to degrade at $353-479 \mathrm{~K}$. The thermal stability of polysiloxane is considerably influenced by oxidative processes. During oxidative degradation, oxygen and free radicals attack the polymer chain indirectly. Their role is limited to the oxidation and cleavage of organic substituents from the silicon which is followed by the formation of new siloxy units, subsequently yielding pure $\left(\mathrm{SiO}_{2}\right)_{\mathrm{x}}$ as the only degradation product above $773-873 \mathrm{~K}$. Comparing PAANa/PAPTMS thermograms, it can be concluded that organic-inorganic hydrogels underwent stages of decomposition similar to PAANa. It is clearly showed that the incorporation of $\mathrm{SiO}_{2}$ into PAANa enhances a thermal stability of the hydrogel, as the evidence by the fact that the thermal degradation temperatures of the hydrogel have shifted to higher temperatures as compared to PAANa. Consequently, the thermograms of PAANa/PAPTMS composites have shown the enhanced thermal stability of samples in comparison with the individual PAANa hydrogel, due to the formation of thermally stable mixed organic-inorganic phase via hydrogen and ionic bonds between carboxylic groups of PAANa and siloxane inorganic network. The corresponding heat-resistance index $\left(T_{\mathrm{HRI}}\right)$ of the PAANa/PAPTMS composites was calculated by Eq. (2): ${ }^{18}$

$$
T_{H R I}=0.49 \cdot\left(T_{5}+0.6 \cdot\left(T_{30}-T_{5}\right)\right)
$$

where $T_{5}$ and $T_{30}$ are the corresponding decomposition temperatures of $5 \%$ and $30 \%$ weight loss, respectively, which are shown in Table 1.

It was shown that the $T_{H R I}$ for PAANa/PAPTMS composites have higher values than those which were calculated by the additive law that is the additional evidence about formation of intercomponent physical interactions. It should be mentioned that the char residue values of all hybrid hydrogels are changed additively. In general, the thermal stability of the studied PAANa/PAPTMS composites remains higher compared to individual compounds that can be explained by the better interfacial compatibility between PAANa and PAPTMS.

The swelling properties of synthesized PAANa/PAPTMS hydrogels were studied and results are presented below. The swelling process in general can be explained by the formation of $\left(\mathrm{H}_{2} \mathrm{O}\right)_{\mathrm{m}}$-bridging groups between the fragments in the individual organic and inorganic phases and mixed PAANa/PAPTMS phase. Thus, the high hydrophilicity of organic and inorganic constituents of hydrogel at the molecular and nanoscale levels provides the destruction of intra- and intermolecular $\mathrm{N}-\mathrm{H} . . . \mathrm{O}=\mathrm{C}$ bonds and formation of $\mathrm{H}$-bonds with water molecules. ${ }^{19}$ The swelling behaviour of PAANa/PAPTMS hydrogels at various $\mathrm{pH}$ is shown in Fig. 3. PAA and PAANa are polyelectrolytes as they possess ionizable groups. The presented data show that the swelling degree at basic medium $(\mathrm{pH}=9.18)$ is greater than in distilled water $(\mathrm{pH}=6.6)$. As at high $\mathrm{pH}$ the carboxylic groups of PAA/PAANa convert to negatively charged carboxylate ions due to a deprotonation process therefore the process of swelling is intensified by the resulting electrostatic repulsion.

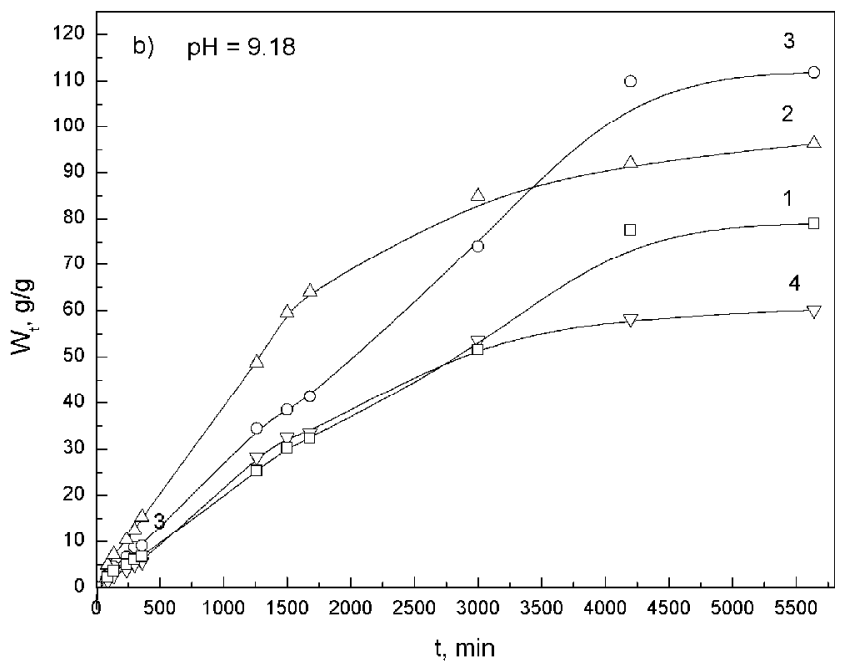

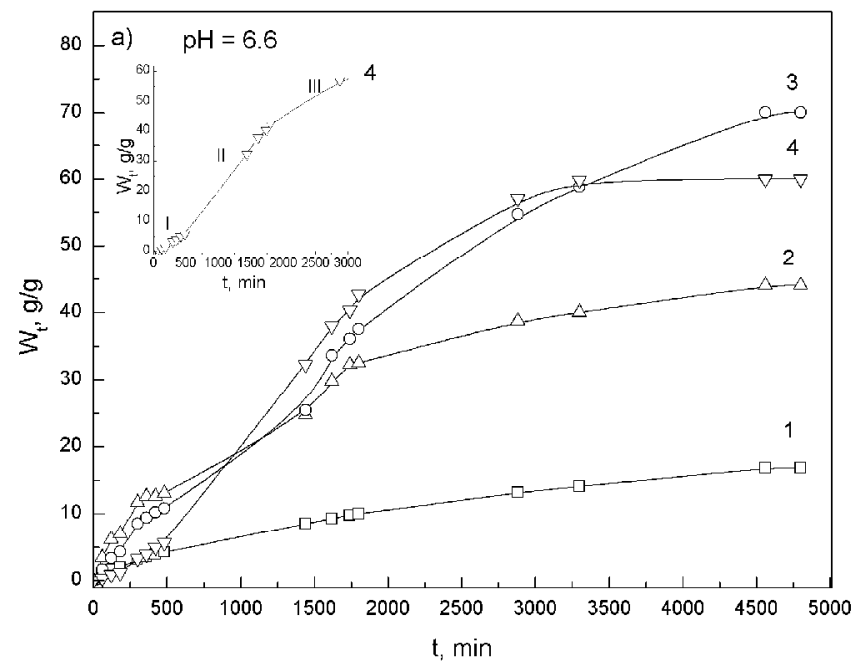

Fig. 3. Sorption isotherms of PAA (1) and PAANa/PAPTMS hydrogels with a component ratio (w/w) of 100/0 (2), 90/10 (3) and 80/20 (4) at different $\mathrm{pH}$ 
The data presented in Table 2 illustrate that the introduction of $10 \mathrm{wt} \%$ of APTMS leads to the increasing of sorption capacity ( $\mathrm{g}$ of $\mathrm{H}_{2} \mathrm{O} / \mathrm{g}$ of composite) in neutral and basic medium. As it is shown in Fig. 3, the sorption capacity of all samples (except PAANa/PAPTMS $=80 / 20$ ) is greater in a basic medium due to ionization of $-\mathrm{COOH}$ groups. The whole swelling process in the water can be characterized by three stages: I) a slow swelling stage; II) an accelerated swelling stage; and III) a gradual swelling until the equilibrium. Firstly, the cooperative physical cross-linking on the networks hinders or restricts the penetration of water molecules inside the hydrogel that results in a slower initial swelling stage. With the increasing of the number of water molecules in the hydrogel and formation of the so-called $\left(\mathrm{H}_{2} \mathrm{O}\right)_{\mathrm{m}}$-bridges, the degree of cooperative physical cross-linking reduces due to the ionization of carboxyl groups and the swelling begins to accelerate. Reaching the certain degree of the ionization of carboxyl groups the cooperative physical cross-links disrupt completely, the swelling process slows down until the maximal ionization of the carboxyl groups, the swelling reaches equilibrium. The duration of the initiation stage affects the whole swelling process, the values of the diffusion parameters and the shape of the kinetic swelling curve. The first stage is much shorter for the samples immersed in the solution with $\mathrm{pH}=9.18$, as a result of intensified deprotonation of carboxylic groups.

The sorption curve of the sample with $20 \mathrm{wt} \%$ content of PAPTMS differs from other samples and is sigmoid in shape (Fig. 3a) with a single point of inflexion at about 50 per cent equilibrium sorption. The sigmoid swelling effect was given many interpretations. For instance, Siegel et $a l .{ }^{20}$ attributed this effect to a swelling front separating the glassy core from the rubbery periphery found in a hydrophobic weak polyelectrolyte of poly[(methyl methacrylate)-co-( $N, N$-dimethylaminomethacrylate)]. The swelling is permitted and accelerated only when the front reaches the core in three dimensions. Díez-Peña and co-workers ${ }^{21}$ assumed that the main factor responsible for the effect of sigmoidal swelling in thermoresponsive poly(N-iPAAm-co-MAA) hydrogels is the disruption of a cooperative physical cross-linking caused by the hydrogen bonds between the carboxyl groups and the amide groups of the hydrogels in a neutral solution in other words the unzipping of the close sites may follow an autocatalytic mechanism. The main idea of this mechanism can be described as the uptake of the first water molecule which helps the uptake of the next one. Up to recent years, a quantitative kinetics equation was given by Diez-Peña $e t a l .^{21}$ for the sigmoid curves appeared in the swelling processes of poly( $N$-iPAAm-co-MAA). The behavior of the swelling curve is greatly changed for PAANa/PAPTMS $=80 / 20$ hydrogel from sigmoid in the distilled water to hyperbolic in basic medium.
The obtained experimental data were used for calculation of diffusion parameters and estimation of the diffusion type. Those types can be generalized by Eq. (3), where the exponent clearly separates the type of diffusion: ${ }^{22}$

$$
\frac{W_{t}}{W_{\infty}}=k \cdot t^{n}
$$

where $k$ and $n$ are constants, $t$ stands for time, and $W_{t} / W_{\infty}$ represents the relation of sorption at any time to sorption at equilibrium.

The $n$ values correlate as follows for the diffusion types: pseudo-Fickian $(n<0.5)$; Fickian (case I) $(n=0.5)$; anomalous or non-Fickian $(0.5<n<1)$; case II $(n=1)$; Super Case II $(n>1){ }^{23,24}$ The process of sorbate diffusion into the polymer is determined by two factors: the migration rate of the sorbate molecules through the polymer network and the relaxation rate of the macrochains of a matrix when they are rearranged during the sorption process.

A plot $\ln \left(W_{t} / W_{\infty}\right) v s . \ln t$ is presented in Fig. 4, data were used to calculate the values of $n$ for hydrogel samples in distilled water and results are presented in Table 2.

The diffusion behaviour of all analyzed samples (except PAANa/PAPTMS $=80 / 20$ ) has anomalous or non-Fickian character. For the explanation of non-Fickian diffusion, one possible mechanism is based on the fact that glassy polymers are not homogeneous throughout the polymer bulk. The non-Fickian mechanism of diffusion appears due to the presence of a sharp front, which separates the dry polymer from the swollen polymer, is assumed to move linearly with time. The disruption of hydrogen bonds starts after penetration of water molecules inside the sample and the decreasing of hydrophobicity occurs due to ionization of carboxylic groups. In fact, this means that the penetration of new water molecules will be easier because the medium becomes more and more hydrophilic. Moreover introduction of inorganic component leads to the increasing of sorption capacity as well as parameter $n$ due to increasing of a number of hydrophilic groups, rearrangement of the network of hydrogen bonds and, as a result, formation of loose organic-inorganic mixed phase.

For studied samples, $n$ parameters have greater values in basic medium that can be explained by intensification of swelling process due to ionization. Significant decrease in duration of the first stage essentially affects the character of swelling curve.

The diffusion behaviour for the sample PAANa/PAPTMS $=80 / 20$ at $\mathrm{pH}=9.18$ is determined as Super Case II $(n>1),{ }^{25}$ when the water penetration rate is much below the polymer chain relaxation rate. 

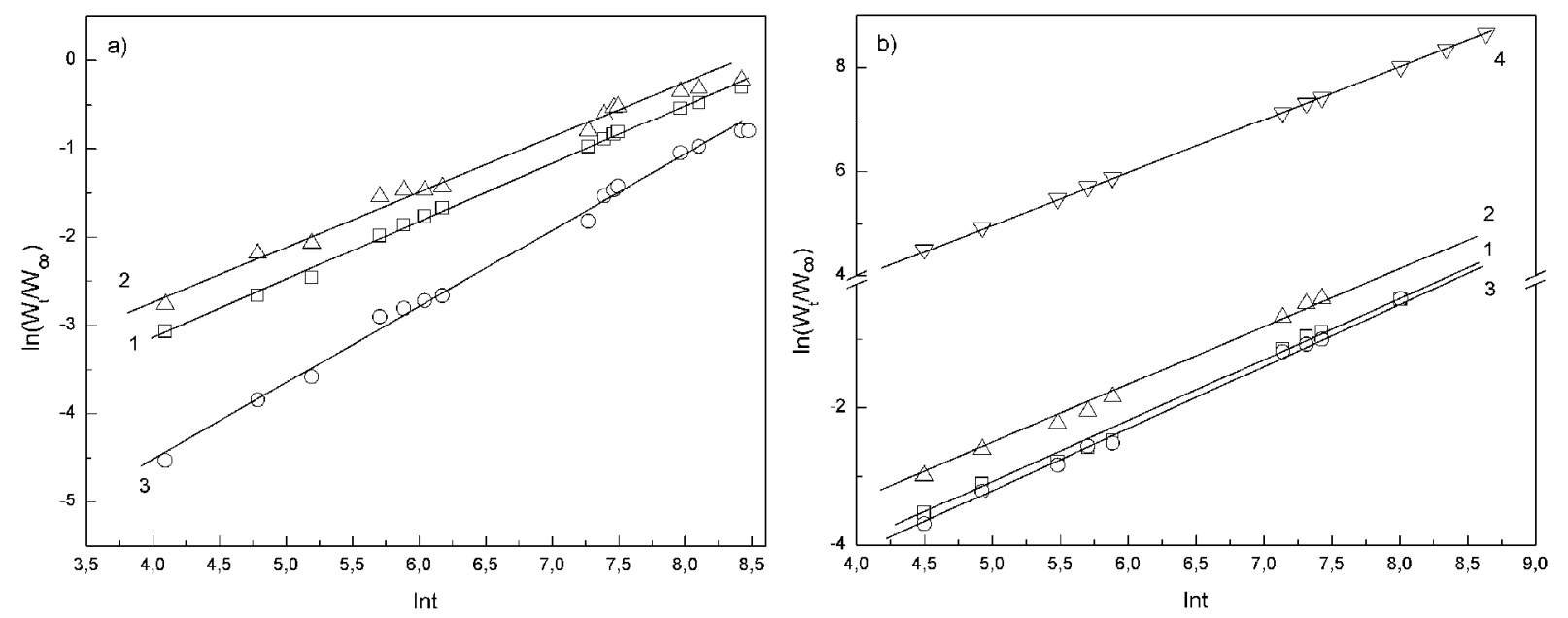

Fig. 4. Swelling behaviour of PAA (1) and PAANa/PAPTMS hydrogels with a component ratio (w/w) of 100/0 (2), 90/10 (3) and $80 / 20$ (4) at $\mathrm{pH}=6.6$ (a) and $\mathrm{pH}=9.18$ (b) in coordinates $\ln \left(W_{t} / W_{\infty}\right) v s . \ln t$

Table 2. Diffusion parameters of individual PAA, PAANa and PAANa/PAPTMS composites

\begin{tabular}{|c|c|c|c|c|c|c|}
\hline \multirow{2}{*}{ Sample } & \multicolumn{3}{|c|}{ Swelling at $\mathrm{pH}=6.6$} & \multicolumn{3}{c|}{ Swelling at $\mathrm{pH}=9.18$} \\
\cline { 2 - 7 } & $W_{\max , \mathrm{g} / \mathrm{g}}$ & $n$ & $R^{2}$ & $W_{\max , \mathrm{g} / \mathrm{g}}$ & $R^{2}$ \\
\hline PAA & 16.81 & 0.65 & 0.997 & 78.92 & 0.922 & 0.996 \\
\hline PAANa & 44.00 & 0.59 & 0.987 & 96.22 & 0.823 & 0.988 \\
\hline PAANa90 & 70.06 & 0.86 & 0.995 & 111.89 & 0.943 & 0.998 \\
\hline PAANa80 & 60.00 & - & - & 60.18 & 1.014 & 0.988 \\
\hline
\end{tabular}

It can be concluded that the swelling behaviour of hydrogels depends on the contribution of penetrant diffusion and polymer relaxation. In the ionic hydrogels the polymer relaxation is affected by the ionisation of functional groups and an increase in the ionization degree results in the electrostatic repulsion between ionized functional groups. This subsequently leads to the chain expansion, and in turn affects the macromolecular chain relaxation. Thus, the swelling mechanism becomes more relaxation-controlled when the ionization of hydrogel increases.

\section{Conclusions}

Novel OIC hydrogels based on PAANa and PAPTMS were synthesized by in situ polymerization of AANa and APTMS. The FTIR spectra confirm that the PAPTMS has been incorporated into the polymeric matrix of the hydrogel. Shifts of characteristic absorption bands of individual components at their mixing are explained by appearing of intercomponent interactions between the constituents of different nature due to the weakening of the intramolecular hydrogen bonds of acrylic fragments of PAANa networks as a result of detachment of the organic polymer chains by the inorganic siloxane network. The experimental results of structuring of OIC hydrogels and intercomponent interaction by means of $\mathrm{H}$-bonds indicate improvements in the thermal stability, as the evidence by the fact that the thermal stability of the composite hydrogel increases as compared to PAANa. In addition to this, it was shown that the $T_{H R I}$ for PAANa/PAPTMS composites have greater values than the additive ones. The incorporation of the PAPTMS increases the swelling capabilities of the novel hydrogel composite. It was revealed that the studied PAANa/PAPTMS organicinorganic hydrogels fit non-Fickian type of water diffusion, which is strongly affected by the ionisation of polymer functional groups. Increasing $\mathrm{pH}$ of swelling media results in deprotonation of carboxylic groups. At the same time, increasing of the content of inorganic constituent till $20 \mathrm{wt} \%$ leads to the changing of diffusion type to the Super Case II at pH 9.18.

\section{References}

[1] Gibas, I.; Janik, H. Review: Synthetic Polymer Hydrogels for Biomedical Applications. Chem. Chem. Technol. 2010, 4, 297-304. https://doi.org/10.23939/chcht04.04.297

[2] Karg, M.; Hellweg, T. Smart Inorganic/Organic Hybrid Microgels: Synthesis and Characterisation. J. Mater. Chem. 2009, 19, 8714-8727. https://doi.org/10.1039/b820292n 
[3] Skorohoda, V.; Melnyk, Y.; Semenyuk, N.; Ortynska, N.; Suberlyak, O. Film Hydrogels on the Basis of Polyvinylpyrrolidone Copolymers with Regulated Sorption-Desorption Characteristics. Chem. Chem. Technol. 2017, 11, 171-174.

https://doi.org/10.23939/chcht11.02.171

[4] Zadeh, M.A.; Grande, A.M.; van der Zwaag, S.; Garcia, S.J. Effect of Curing on the Mechanical and Healing Behaviour of a hybrid Dual Network: A Time Resolved Evaluation. RSC Adv. 2016, 6, 91806-91814. https://doi.org/10.1039/C6RA17799A

[5] Saito, J.; Furukawa, H.; Kurokawa, T.; Kuwabara, R.; Kuroda, S.; Tanaka, Y.; Gong, J.P.; Kitamura, N.; Yasuda, K. Robust Bonding and One-Step Facile Synthesis of Tough Hydrogels with Desirable Shape by Virtue of the Double Network Structure. Polym. Chem. 2011, 2, 575-580. https://doi.org/10.1039/C0PY00272K

[6] Gong, J.P.; Katsuyama, Y.; Kurokawa, T.; Osada, Y. DoubleNetwork Hydrogels with Extremely High Mechanical Strength. $A d v$. Mater. 2003, 15, 1155-1158.

https://doi.org/10.1002/adma.200304907

[7] Nakajima, T.; Fukuda, Y.; Kurokawa, T.; Sakai, T.; Chung, U.I.; Gong, J.P. Synthesis and Fracture Process Analysis of Double Network Hydrogels with a Well-Defined First Network. ACS Macro. Lett. 2013, 2, 518-521. https://doi.org/10.1021/mz4002047 [8] Chen, Q.; Zhu, L.; Chen, H.; Yan, H.; Huang, L.; Yang, J.; Zheng, J. A Novel Design Strategy for Fully Physically Linked Double Network Hydrogels with Tough, Fatigue Resistant, and Self-Healing Properties. Adv. Funct. Mater. 2015, 25, 1598-1607. https://doi.org/10.1002/adfm.201404357

[9] Xue, S.; Wu, Y.; Guo, M.; Liu, D.; Zhang, T.; Lei, W. Fabrication of Poly(acrylic acid)/Boron Nitride Composite Hydrogels with Excellent Mechanical Properties and Rapid SelfHealing Through Hierarchically Physical Interactions. Nanoscale Res. Lett. 2018, 13, 393-402. https://doi.org/10.1186/s11671-0182800-2

[10] Zhong, M.; Liu, Y.-T.; Xie, X.-M. Self-Healable, Super Tough Graphene Oxide-poly(acrylic acid) Nanocomposite Hydrogels Facilitated by Dual Cross-Linking Effects through Dynamic Ionic Interactions. J. Mater. Chem. B 2015, 3, 4001-4008.

https://doi.org/10.1039/C5TB00075K

[11] Bhatia, M.; Rajulapati, S.B.; Sonawane, S.; Girdhar, A. Synthesis and Implication of Novel Poly(acrylic acid)/Nanosorbent Embedded Hydrogel Composite for Lead Ion Removal. Sci. Rep. 2017, 7, 16413. https://doi.org/10.1038/s41598-017-15642-9

[12] Zhang, Y.; Gao, P.; Lin, Z.; Chen, Y. Preparation and Swelling Properties of a Starch-g-poly(acrylic acid)/Organo-Mordenite Hydrogel Composite. Front. Chem. Sci. Eng. 2016, 10, 147-161. https://doi.org/10.1007/s11705-015-1546-y

[13] Shen, J.; Yan, B.; Li, T.; Long, Y.; Li, N.; Ye, M. Mechanical, Thermal and Swelling Properties of Poly(acrylic acid)-Graphene Oxide Composite Hydrogels. Soft Matter 2012, 8, 1831-1836. https://doi.org/10.1039/C1SM06970E

[14] Rubio, J.; Mazo, M.A.; Martín-Ilana, A.; Tamayo, A. FT-IR Study of the Hydrolysis and Condensation of 3-(2-Aminoethylamino)propyl-trimethoxy Silane Estudio FT-IR de la Hidrólisis y Condensación del 3-(2-Amino-etilamino)propil-trimetoxi silano. Bol. Soc. Esp. Cerám. 2018, 57, 160-168.

https://doi.org/10.1016/j.bsecv.2017.11.003

[15] Chen, Y.; Chen, Q.; Song, L.; Li, H.-P.; Hou, F.-Z. Preparation and Characterization of Encapsulation of Europium Complex into Meso-Structured Silica Monoliths Using PEG as the Template.

Micropor. Mesopor. Mat. 2009, 122, 7-12.

https://doi.org/10.1016/j.micromeso.2008.12.021
[16] Zhang, X.; Bhuvana, S.; Loo, L.S. Characterization of Layered Silicate Dispersion in Polymer Nanocomposites Using Fourier Transform Infrared Spectroscopy. J. Appl. Polym.Sci. 2012, 125, E175-E180. https://doi.org/10.1002/app.36266

[17] Carraher, C.E. Jr. Thermal Characterizations of Inorganic and Organometallic Polymers. J. Macromol. Sci., Chem. A. 1982, 17, 1293-1356. https://doi.org/10.1080/00222338208074401

[18] Tang, L.; Dang, J.; He, M.; Li, J.; Kong, J.; Tang, Y.; Gu, J. Preparation and Properties of Cyanate-Based Wave-Transparent Laminated Composites Reinforced by Dopamine/POSS

Functionalized Kevlar Cloth. Compos. Sci. Technol. 2019, 169, 120126. https://doi.org/10.1016/j.compscitech.2018.11.018

[19] Alam, M.A.; Takafuji, M.; Ihara, H. Thermosensitive Hybrid Hydrogels with Silica Nanoparticle-Cross-Linked Polymer Networks. J. Colloid Interface Sci. 2013, 405, 109-117.

https://doi.org/10.1016/j.jcis.2013.04.054

[20] Siegel, G.M. Stuttering and Behavior Modification: Commentary. J Fluency Disord. 1993, 18, 109-114. https://doi.org/10.1016/0094730X(83)90007-4

[21] Díez-Peña, E.; Quijada-Garrido, I.; Barrales-Rienda, J.M. Hydrogen-Bonding Effects on the Dynamic Swelling of P(N-iPAAmco-MAA) Copolymers. A Case of Autocatalytic Swelling Kinetics. Macromolecules 2002, 35, 8882-8888.

https://doi.org/10.1021/ma020895v

[22] Li, S.; Liu, X.; Zou, T.; Xiao, W. Removal of Cationic Dye from Aqueous Solution by a Macroporous Hydrophobically Modified Poly(acrylic Acid-acrylamide) Hydrogel with Enhanced Swelling and Adsorption Properties. Clean-Soil Air Water 2010, 38, 378-386. https://doi.org/10.1002/clen.200900220

[23] Zhang, M.; Cheng, Z.; Zhao, T.; Liu, M.; Hu, M.; Li, J. Synthesis, Characterization, and Swelling Behaviors of Salt-Sensitive Maize Bran-Poly(acrylic acid) Superabsorbent Hydrogel. J. Agric. Food Chem. 2014, 62, 8867-8874. https://doi.org/10.1021/jf5021279 [24] Kaşgöz, H.; Durmus, A. Dye Removal by a Novel HydrogelClay Nanocomposite with Enhanced Swelling Properties. Polym. Advan. Technol. 2008, 19, 838-845. https://doi.org/10.1002/pat.1045 [25] Munday, D.L.; Cox, P. Compressed Xanthan and Karaya Gum Matrices: Hydration, Erosion and Drug Release Mechanisms. Int. J. Pharm. 2000, 203, 179-192. https://doi.org/10.1016/S03785173(00)00444-0

Received: July 28, 2020 / Revised: August 12, 2020 / Accepted: October 10, 2020

\section{ВПЛИВ ПОХІДНОЇ ДІАМІНОСИЛАНУ НА ТЕРМІЧНІ ВЛАСТИВОСТІ І ЗДАТНІСТЬ ДО НАБУХАННЯ ГІДРОФІЛЬНИХ КОМПОЗІТІВ НА ОСНОВІ АКРИЛОВОї КИСЛОТИ}

\begin{abstract}
Анотація. Показано, щзо органо-неорганічні гідрофільні композити на основі частково нейтралізованої поліакрилової кислоти (ПАANa) та полі- $N$-(2-аміноетил)-3-амінопропілтріметоксисилану (ПАПТМС) виявляють покращену здатність до набухання при використанні ПАПТМС. Встановлено, щсо при вмісті ПАПТМС $20 \%$ мас. Тип дифузї змінюеться на Super Case II. Визначено, цио термостабільність та індекс термостійкості композитних гідрогелів у порівнянні з ПАANа є вищими.
\end{abstract}

Ключові слова: поліакрилова кислота, гідрогель, органо-неорганічні композити, набухання. 